\title{
ACESSO À INFORMAÇÃO, DEBATE PÚBLICO E DIREITO AO DESENVOLVIMENTO
}

\author{
ACCESS TO INFORMATION, PUBLIC DEBATE AND DEVELOPMENT LAW
}

\author{
Andy Portella Battezini \\ Advogada, especialista em Direito Tributário e Gestão de Pessoas pela Universidade \\ Anhanguera - Uniderp. Mestranda em Direito Democracia e Sustentabilidade pela \\ Faculdade Meridional. Menbro do grupo de pesquisa Direito, Novas Tecnologias e \\ Desenvolvimento. E-mail: andy_battezini@ hotmail.com
}

Karla Cristine Reginato

Advogada, Pós-graduanda em Direito Previdenciário pela Rede de Ensino Luiz Flávio Gomes-Anhanguera Uniderp. Mestranda em Direito pela Faculdade Meridional.

karlacreginato@hotmail.com

Neuro José Zambam

\begin{abstract}
Pós-doutor em Filosofia na Universidade do Vale do Rio dos Sinos - UNISINOS. Doutor em Filosofia pela PUCRS. Professor do Programa de Pós-graduação em Direito da

Faculdade Meridional - IMED - Mestrado. Professor do Curso de Direito (graduação e especialização) da Faculdade Meridional - IMED de Passo Fundo/RS. Membro do Grupo de Trabaᄀlho, Ética e cidadania da ANPOF (Associação Nacional dos Programas de Pósgraduação em Filosofia). Pesquisador da Faculdade Meridional. Coordenador do Grupo de Pesquisa: Multiculturalismo, minorias, espaço público e sustentabilidade. Líder do Grupo de Pesquisa, Multiculturalismo e pluralismo jurídico. Líder do Centro Brasileiro de

Pesquisa sobre a Teoria da Justiça de Amartya Sen: interfaces com direito, políticas de desenvolvimento e democracia. E-mail: neurojose@hotmail.com; nzambam@imed.edu.br
\end{abstract}

Recebido em: 05/11/2016

Aprovado em: 27/01/2017

Doi: $10.5585 /$ rdb.v16i7.530

RESUMO: Este artigo tem como objetivo demonstrar a importância do acesso à informação e da ampliação dos mecanismos de participação para a construção de democracia e das políticas de desenvolvimento. A fundamentação desta exposição tem como referência a Teoria da justiça de Amartya Sen e suas pesquisas reconhecidas nos diversos campos da investigação científica e da atuação política. O método que sustenta essa investigação é o dedutivo, a técnica pesquisa bibliográfica e a categoria operacional. As sociedades democráticas quando organizadas para garantir direitos, especificamente o acesso à informação, o debate público e a ampla participação fomentam políticas de desenvolvimento que promovem a dignidade humana, o exercício da liberdade e a justiça social.

Palavras-chave: Democracia. Desenvolvimento. Direito à Informação. Participação.

ABSTRACT: This article aims to demonstrate the importance of access to information and extension of participation mechanisms for building democracy and development policies. The 
basis of this exhibition is to reference the Theory of Justice by Amartya Sen and its recognized research in various fields of scientific research and political action. The method that supports this research is deductive, the technical literature and the operational category. The democratic societies when organized to ensure rights, specifically access to information, the public debate and broad participation foster development policies that promote human dignity, the exercise of freedom and social justice.

Key words: Democracy. Development. Right to Information. Participation.

SUMÁRIO: Introdução; 1. O Direito à Informação e a Transparência Administrativa; 2. Acesso à Informação e Democracia Participativa; 3. O Direito à informação como suporte para o desenvolvimento das liberdades civis; Conclusão; Referências.

\section{INTRODUÇÃO}

O direito à informação é um direito humano e fundamental, estando cada vez mais consolidado no âmbito do espaço democrático. A Constituição Federal Brasileira adotou o regime Democrático, que consagra a informação como um dos pilares do conhecimento e da cooperação no processo de emancipação. Nesse sentido, o acesso à informação representa uma mudança de paradigma, pautado no direito que toda e qualquer pessoa possui: de se informar e ser informado, principalmente no tocante às questões envolvendo a ordem pública e o interesse social.

Este tema apresenta-se relevante, tendo em vista que diversos ordenamentos jurídicos de países em desenvolvimento como é o caso do Brasil, já estão incorporando em seus textos legais normas específicas que dizem respeito ao direito de informação, a fim de dar mais efetividade e transparência nos procedimentos governamentais, que juntamente com o auxílio das novas tecnologias de informação e comunicação, contribuem para ampliar os espaços de discussão, sem delimitar territórios ou fronteiras. Nesse aspecto, permeia-se o desejo de fomentar o debate público, por meio de uma atuação proativa dos cidadãos e seus governantes a luz do Estado Democrático de Direito.

Para isso, busca-se responder a seguinte a questão de pesquisa: O poder Estatal, no uso de suas atribuições, tem garantido aos cidadãos o exercício do direito pleno de acesso às informações, bem como a utilização de instrumentos capazes de promover uma democracia participativa?

Nesse viés, o objetivo geral é demonstrar a importância da participação popular nas tomadas de decisões políticas para a promoção de uma maior transparência, e, consequentemente, menor corrupção na seara governamental. Enquanto, os objetivos específicos consistem em a) analisar as dimensões que se concentram no campo conceitual e jurídico do direito à informação; b) evidenciar o papel da participação democrática no cenário contemporâneo, e ainda c) delimitar a perspectiva destes fundamentos sob o pressuposto do desenvolvimento como garantidor das liberdades civis.

A presente pesquisa está dividida em três capítulos. No primeiro será trabalhado a definição do Direito à Informação, a sua previsão no ordenamento jurídico pátrio, além de evidenciar a forma em que as novas tecnologias de informação e comunicação vêm sendo indispensáveis na conjuntura atual.

No segundo busca-se destacar a indispensabilidade do acesso a informação e da participação política na construção da democracia colaborativa, com ênfase ao papel da Lei de Acesso a Informação, que em conjunto com a accountability interage na formulação de políticas de transparência e de cooperação entre governo e sociedade. 
Enquanto, no terceiro e último capítulo discorrer-se-á o aporte teórico de Amartya Sen sobre o estudo da argumentação e do debate público como instrumentos determinantes para o desenvolvimento e de uma democracia compreendida como um "governo em forma de debate" .

Para a construção da presente pesquisa utilizar-se-á o método dedutivo. O método de procedimento será tipológico, pois pretende-se indicar um modelo adequado de participação popular na esfera democrática. A técnica de pesquisa concentra-se na investigação bibliográfica de textos doutrinários, meios eletrônicos e coleções particulares.

\section{O DIREITO À INFORMAÇÃO E A TRANSPARÊNCIAADMINISTRATIVA}

A informação apresenta-se como direito fundamental e revela-se de grande importância para o contexto jurídico-social, pois além de viabilizar as informações relativas aos órgãos públicos, também pode e deve ser reconhecida como um princípio garantidor da transparência administrativa, vindo a ser um pré-requisito essencial para o livre exercício da cidadania, já que um dos seus principais pilares vem a ser a promoção e aprimoramento da participação pública no processo democrático. Sua legitimidade é consagrada, inclusive, em importantes instrumentos no âmbito do direito internacional como a Declaração Universal dos Direitos do Homem $(\mathrm{ONU})^{2}$, desde o ano de 1948, o Pacto Internacional de Direitos Civis e Políticos, ${ }^{3}$ assim como na Declaração dos Princípios Fundamentais Relativos ao Fortalecimento da Paz e da Compreensão Internacional à Promoção dos Direitos Humanos e à Luta contra o Racismo e a Apartheid, e a limitação a guerra, está última proclamada em $1978^{4}$.

No Sistema Constitucional Brasileiro, o Direito à Informação encontra-se amparado no artigo $5^{\circ}$, inciso XIV do Texto Legal, o qual "reconhece a todos o acesso à informação e resguardado o sigilo da fonte, quando necessário ao exercício profissional" entendido como o direito de pesquisar, auferir e transmitir conhecimento por meio de instrumentos adequados, visando assim, cooperar, inclusive, com o fortalecimento da democracia.

É um direito não apenas dos profissionais de imprensa e dos indivíduos, mas também das atividades executadas pelo Estado, pois está em plena consonância com o princípio da publicidade, o qual atribui o dever de fornecer, a título de conhecimento, os procedimentos da administração pública. Apesar de impor maior transparência nas ações das entidades estatais, esse direito, todavia, sofre algumas restrições, como é o caso de matérias sigilosas, as quais a discrição é indispensável para a segurança da coletividade e do próprio Estado, principalmente em matérias que envolvam a intimidade das pessoas, e a proteção de comunicação e dados fiscais, conforme prevê a Constituição Federal ${ }^{6}$.

Segundo Cepik ${ }^{7}$, no conteúdo desse direito está inserido um leque de princípios legais que visam a "assegurar que qualquer pessoa ou organização tenha acesso a dados sobre si mesma

\footnotetext{
${ }^{1} \mathrm{O}$ presente autor dará o aporte teórico a pesquisa. SEN. Amartya. Desenvolvimento como liberdade. Tradução Laura Teixeira Motta. São Paulo: Companhia das Letras, 2000, p. 358.

${ }^{2}$ Artigo 13 - Toda pessoa tem direito à liberdade de pensamento e de expressão. Esse direito compreende a liberdade de buscar, receber e difundir informações e ideias de toda natureza, sem consideração de fronteiras, verbalmente ou por escrito, ou em forma impressa ou artística, ou por qualquer outro processo de sua escolha.

${ }^{3}$ MENDEL, Toby. Liberdade de informação: um estudo de direito comparado. 2.ed. Brasília, DF: UNESCO, 2009. Disponível em: <http://www.acessoainformacao.gov.br/acessoainformacaogov/publicacoes/liberdade-informacaoestudo-direito-comparado-unesco.pdf>. Acesso em: 17 jun. 2016.

${ }^{4}$ GONÇALVES, Ângela. Argumentação racional pública e democracia. Revista Opinião Filosófica, Porto Alegre, v. $03 ; n^{\circ} .01,2012$.

${ }^{5}$ BRASIL, Constituição Federal de 1988.

${ }^{6}$ Art $5^{\circ}$ e artigo 93

${ }^{7}$ CEPIK, Marco. Direito à Informação: Situação Legal e Desafios. Revista IP - Informática Pública, Belo Horizonte, v. 02, n. 02, p. 43-56, dez. 2000.
}

Revista de Direito Brasileira | São Paulo, SP | v. 16 | n. 7 | p. 242 - 255 | Jan./Abr. 2017 
que tenham sido coletados e estejam armazenados em arquivos e bancos de dados governamentais e privados", além de informações públicas que disponham sobre o governo, a administração pública e o país.

O Direito à Informação, conforme apresenta Carvalho, divide-se em duas vertentes: o direito de emitir e receber informação e o dever de informar. ${ }^{8}$ Tal direito, mais precisamente nos últimos anos, tem conquistado ainda mais espaço na esfera política, principalmente no tocante as informações entre governantes e particulares, diante das situações que envolvam maior interesse social $^{9}$, isso tudo vem de encontro ao desejo por uma política cada vez mais transparente e de livre acesso a população.

Além do mais, salienta-se que o processo de informação e debate entre os cidadãos é representado desde os primórdios gregos, tornando-se peça fundamental para tomada de decisões e de planejamento no modelo de democracia daquela época. O uso da comunicação era executado nas praças públicas da chamada pólis, de modo a viabilizar o direito à voz e ao voto aos cidadãos Atenienses. Essa aproximação entre os cidadãos gregos nas ágoras-públicas tinha o compromisso de incentivar o debate, impulsionando os ideais políticos na história, visto que o papel da comunicação, assim, "contribuía no dia-a-dia para constituir e formalizar a comunidade grega integrando todos os seus participantes", como bem coloca Hohfeldt ${ }^{10}$.

O processo de comunicação, concebido desde o período Grego e perpassando pelos mais diversos períodos de civilização, permitiu mais do que a simples troca de informação e diálogos do que acontecia no contexto político-social, mas também na própria manutenção da opinião consensual $^{11}$, que até hoje figura como procedimento essencial nas relações entre poder e sociedade.

Nesse viés, o Direito à Informação tem importância decisiva para o desenvolvimento do estado e da pessoa para o exercício da cidadania, pois, de acordo com o ensinamento de Viegas "há que se compreender que com uma maior transparência por parte da Administração, ficaria claro que diminuiria, por conseguinte, a desconfiança no governo ${ }^{12}$ ". Por isso a necessidade em conceber a informação não apenas como um direito fundamental 131 , mas sim, um direito humano, que tem como escopo atingir outros direitos igualmente constitucionais e de relevância fundamental ${ }^{14}$ que consagram a busca por uma sociedade paritária.

A informação, vista por este prisma, pode ser identificada e concebida em múltiplas facetas: na ótica social, política e, até mesmo, humana. Na ausência de acesso à informação, não há educação, nem o desenvolvimento para concepção da liberdade humana, esta última fundamental para o exercício da cidadania e da própria democracia. Nessa ordem de ideias, é preciso avançar e reconhecer que o acesso a informação pode ser expandido e disseminado entre os povos, e ainda, se aliado aos novos meios de comunicação digital pode vir a contribuir ainda

\footnotetext{
${ }^{8}$ CARVALHO, Luiz Gustavo Grandinetti Castanho de. Liberdade de informação e o direito difuso à informação verdadeira. Rio de Janeiro: Renovar, 2003, p. 88.

${ }^{9}$ Nesse caso pode-se mencionar as manifestações políticas ocorrida nos anos de 2015 e 2016 que consubstanciou no impeachment da presidente Dilma Roussef. Disponível em: http://brasil.elpais.com/brasil/2016/03/13/politica/1457906776 440577.html. Acesso em 25 set. 2016.

${ }_{10}$ HOHLFELDT, Antônio. As origens antigas: a comunicação e as civilizações. In: _; et al. Teorias da Comunicação: conceitos, escolas e tendências. Petrópolis: Vozes, 2007, p. 80.

${ }^{11}$ HOHLFELDT, 2007, p.88.

${ }^{12}$ VIEGAS, Weverson da Siva. O direito à informação como pressuposto para a participação popular no Estatuto da Cidade. Revista da Faculdade de Direito de Campos, Campos dos Goytacazes, RJ, v. 4/5, n. 4/5, p. 671-683, 2003/2004. Disponível em: <http://bdjur.stj.jus.br/dspace/handle/2011/25696>. Acesso em: 26 set. 2016.

${ }^{13}$ VIEGAS, 2004.

${ }^{14}$ SADALLA BUCCI, Eduardo. O acesso à informação pública como direito fundamental à cidadania. In: Âmbito Jurídico, Rio Grande, XII, n. 67, ago 2009. Disponível em: <http://www.ambitojuridico.com.br/site/index.php?n_link=revista_artigos_leitura\&artigo_id=6490

>. Acesso em 16 jun 2016.
}

Revista de Direito Brasileira | São Paulo, SP | v. 16 | n. 7 | p. 242 - 255 | Jan./Abr. 2017 
mais para o espaço de debate, instrução e de conhecimento das questões públicas, vindo inclusive a remodelar e dar um novo sentido ao direito à informação.

Com a presença das Novas Tecnologias de Informação e Comunicação (TIC'S) forma-se uma nova era de conhecimento e de comunicação, pois na medida em que aumenta exponencialmente a velocidade com que as informações são transmitidas, esse novo espaço ajuda a dinamizar as articulações em sociedade por meio do uso da Internet, instituindo um novo modelo de propalar informações entre as pessoas, cuja finalidade permeia um novo ambiente informacional em que "a Internet não é um meio de comunicação, mas uma plataforma de comunicação de pessoas", conforme anuncia Cremades ${ }^{15}$.

Pode-se afirmar que o direito à informação caracteriza-se como um novo direito do cidadão em detrimento da administração pública, de modo a constituir a nova égide do Estado Moderno Democrático em que, segundo Neto: "A importância jurídica da comunicação evidencia-se a partir do momento em que a normatização deixa de ter o indivíduo como único centro de preocupação e desloca-se para o social, para o reflexo da conduta individual sobre o tecido social" $"$.

Ainda, conforme o prenuncia Neto

[...] A ampla baliza constitucional para a comunicação social abrange todas as espécies de transmissão de massa de informações, inclusive publicidade e propaganda, havendo entendimento de que abarca a Internet e as comunicações por e-mail - mesmo porque este ademais é campo de abrangência do Direito da Comunicação Social - e traz ainda outra importante limitação: o respeito aos valores éticos e sociais da pessoa e da família. ${ }^{17}$

Destarte que o fundamento da informação é amplo, pois compreende a própria liberdade dos cidadãos em intensificar as relações sociais a nível mundial. Por isso que na essência do regime democrático deve constar o acesso à livre informação, pois onde não há diálogo, não se pode pensar em uma democracia participativa. Por isso a necessidade em avaliar as razões e a vinculação entre democracia e participação civil, como forma de defesa e reinvindicação popular na formação política contemporânea.

\section{ACESSO À INFORMAÇÃO E DEMOCRACIA PARTICIPATIVA}

A importância da informação no cenário democrático é imprescindível, pois a opinião pública e o debate permitem conquistar cada vez mais espaço, fazendo com que a informação seja a protagonista nas plataformas de discussão aberta, fundamento essencial para a constituição de uma sociedade democrática, considerando que sem informação ou liberdade de expressão a verdadeira democracia resta comprometida, já que a livre circulação de ideias é pressuposto para o governo do povo ${ }^{18}$.

Os valores constitucionais de uma liberdade comunicativa global é o ponto de encontro com os valores da democracia, da liberdade, da igualdade e da justiça, todos assegurados no preâmbulo da Constituição Federal. Sendo assim, percebe-se que o direito à informação é um importante aliado e pressuposto basilar do regime democrático. Carlos Santiago Nino-j já

\footnotetext{
${ }^{15}$ CREMADES, Javier. Micropoder - a força do cidadão na era digital. São Paulo: SENAC, 2009, p. 204.

${ }^{16}$ NETO, Guilherme Fernandes. Direito da Comunicação Social. São Paulo: Editora Revista dos Tribunais, 2004, p. 34.

${ }^{17}$ NETO, 2004, p. 34.

${ }^{18}$ Voto proferido pelo Ministro do Supremo Tribunal Federal Brasileiro, Carlos Ayres Britto na Medida Cautelar (ADPF) arguição de descumprimento de preceito fundamental n. 130-7 em 21.02.2008.
} 
afirmava que a crise da democracia nunca decorreu do excesso de participação na tomada de decisões, mas sim, na apatia política destes ${ }^{19}$.

Galindo Ayuda da mesma forma atribui a participação popular como fundamento basilar de uma democracia representativa. Ou seja, a participação é pré-condição para formação de um sistema político democrático capaz de estimular a participação dos cidadãos no controle sobre as ações do Estado, ou ainda, como pode se observar:

[...] en la actualidad cabe decir, sintéticamente, que un sistema político democrático es aquel cuyo funcionamiento está basado en la participación consciente e informada de los ciudadanos en el ejercicio del poder político o bien indirectamente mediante la elección de sus representantes o bien directamente colaborando en la toma de decisiones políticas utilizando otros mecanismos. ${ }^{20}$

Nesse ponto, percebe-se que a busca pela-concretização plena da democracia está intimamente relacionada nas formas de participação e atuação por parte dos agentes sociais. A informação é uma necessidade irrenunciável, sem a qual se torna difícil consolidar a existência de uma democracia livre e justa. As discussões públicas são percussoras e condicionais para a "democracia viva" proposta por Muller.

O povo, nesse novo sentido, não é mais uma "maioria calada", que nada faz quando entrega o seu voto a cada quatro ou cinco anos. Rousseau escarneceu já há 250 anos (a exemplo da Inglaterra) essa caricatura de "povo" do estado. Infelizmente, a caricatura continuou dominante até o final do século XX. Mas agora o povo participa no pano de fundo como ator da história. Os direitos humanos e dos cidadãos é base normativa para tanto. As autoridades e regimes reprimem esses direitos; os direitos constitucionais exercidos são - ao contrário - uma condição necessária para a Democracia sob o aspecto institucional e procedimental. Apenas uma condição "necessária", ou seja, não podem simplesmente substituir por completo a Democracia. Entretanto, qualquer Democracia viva está apoiada em direitos constitucionais: liberdade de informação e de opinião, liberdade dos sindicatos e de suas atividades, liberdade dos partidos políticos, liberdade de reunião, demonstração e de associação, direito de escolha livre e imediata, etc. ${ }^{21}$

A intuito do direito à informação na análise do contexto, entende-se que não deve se restringir apenas ao direito individual de auferir e transmitir conhecimentos sobre atos privados ou públicos. Seu escopo é abrangente, especialmente no interesse da própria coletividade em difundir uma democracia cada vez mais transparente e sólida em conjunto com os demais princípios democráticos de direito, em especial o princípio da liberdade de expressão e da publicidade, para assim avançar na promoção de um espaço público integrado com a pluralidade de interesses sociais.

\footnotetext{
${ }^{19}$ NINO, Carlos Santiago. La Constitucion de la Democracia Deliberativa.1. ed., 1 reimp. Barcelona: Gedisa Editorial, 2003.

${ }^{20}$ AYUDA, Fernando Galindo. Democracia, Internet y Gobernanza: una concreción. Revista Sequiência, Florianópolis, v. 33, n. 65, p. 33-56, 2012, p. 37.

${ }^{21}$ MULLER, Friederich. Democracia e República. In Rev. Jur. Brasília, v.7, n. 77, p. 01-07, fev./mar.2006. p.6. Disponível em: http://www.planalto.gov.br/ccivil_03/revista/Rev_77/artigos/PDF/FriederichM\%FCller_Rev77.pdf. Acesso em 05 de jun. de 2016.
} 
A democracia é o regime de governo legitimado pelo povo, sendo que na obra de Boaventura Souza Santos ${ }^{22}$ ela pode ser reconhecida sob duas vertentes: a democracia representativa e a democracia participativa. Ambas as formas de democracia foram incorporadas pelo sistema pátrio, sendo que a primeira é exercida através do voto - universal e direto, no qual, através a maioria dos cidadãos, elege as pessoas do povo para representá-los e governá-los. Já, em contrapartida, está a democracia participativa, aquela em que o povo participa efetivamente, seja fiscalizando os atos de seus representantes ou opinando diretamente sobre alguma política pública, a exemplo das consultas de orçamento municipal, em que há a influência da população na alocação dos recursos públicos.

O exercício da democracia participativa é fundamental, pois é por meio dela que a sociedade passa a ter conhecimento dos atos e omissões praticadas por seus governantes. No momento em que a sociedade participa efetivamente das decisões políticas, aumenta ainda mais a fiscalização, e consequentemente, o processo de transparência das instituições, que com a globalização e o auxílio das ferramentas midiáticas, como é a Internet, em um curto espaço de tempo, pode elevar a capacidade dos cidadãos em participar de decisões que os atinja.

Com a finalidade de promover uma maior participação democrática, o direito à informação ganhou um novo enfoque com entrada em vigor na Lei de Acesso Informação Pública, a Lei n. $12.527 / 11^{23}$, como o mecanismo de transparência e combate à corrupção, inclusive consagrando a proteção do acesso à informação como direito humano e fundamental.

A Lei de Acesso a informação deu um passo importante na consolidação do regime democrático, pois além de ampliar o espaço de participação cidadã, a referida lei veio a fortalecer o controle da gestão pública, possibilitando assim que qualquer pessoa possa obter informações e documentos de manutenção do Estado, desde que não tenha caráter pessoal ou esteja submetido por sigilo.

Segundo a Controladoria Geral da União ${ }^{24}$, o cidadão bem informado possui melhores condições de conhecer e acessar outros direitos essenciais, como a saúde, a educação e os benefícios sociais. No quesito cultural, o acesso e o fluxo de informações favorecem a tomada de decisões, a boa gestão de políticas públicas e a inclusão do cidadão. Logo, "o acesso à informação constitui uma ferramenta essencial para combater a corrupção, transforma em realidade o princípio da transparência na gestão pública e melhora a qualidade das nossas democracias". 25

Nesse sentido, a lei é clara quanto à prescrição e aos objetivos a serem adotados no âmbito das três esferas do poder. Advertir no âmbito de suas competências informações de interesses coletivos ou gerais, de modo a incentivar a realização de consultas públicas, debates e proteção contra a negação de prestação de informações, sem, contudo, excluir aqueles que ainda não estão inseridos nos meios eletrônicos representa um dos alicerces da legislação. Isso tudo sem comprometer os menos favorecidos, já que a autoridade tem o dever de custear ou promover locais de fácil acesso que assegurem a participação de todos.

\footnotetext{
${ }^{22}$ SANTOS, Boaventura de Sousa e AVRITZER, Leonardo. Para ampliar o cânone democrático. In: SANTOS, Boaventura de Sousa (org.). Democratizar a democracia: os caminhos da democracia participativa. Rio de Janeiro: Civilização Brasileira, 3a ed. 2005.

${ }^{23}$ BRASIL. Controladoria Geral da União. Acesso à informação pública: uma introdução à Lei 12.527 , de 18 de novembro de 2011. Brasília, 2011. Disponível em:<http://www.cgu.gov.br/acessoainformacao/materiaisinteresse/CartilhaAcessoaInformacao.pdf >. Acesso em: 19 mai. 2016.

${ }^{24}$ BRASIL. Transparência pública. 2011.2 Disponível em:<http://www.portaltransparencia.gov.br/controleSocial/documentos/FolderTransparencia.pdf >. Acesso em: 19 mai. 2016.

${ }^{25}$ MANZANO FILHO, Gabriel. OEA defende o direito à informação. 2012 . Disponível em:<http://www.mndh.org.br/index.php?option=com_content\&task=view\&id=113\&Itemid=45>. Acesso em: 19 mai. 2016.
} 
Nesse mesmo cenário a accountability aponta como importante mecanismo de controle social e de transparência por parte dos governantes. O termo ainda não possui tradução definitiva para o português, mas pode ser compreendido como "conjunto de mecanismos e procedimentos que levam os decisores governamentais a prestar contas dos resultados de suas ações, garantindose maior transparência e a exposição das políticas públicas" é o que aponta Jardim. ${ }^{26}$

Essa ideia de transparência refere-se a um imperativo do Estado Moderno, que, por mais aberto que seja o seu conceito, está intimamente relacionado aos modos de interação entre o Estado e os sistemas sociais em busca da cooperação, respeito mútuo, e consequentemente na participação da coletividade nos processos decisórios. ${ }^{27}$ A concretização da transparência com a accountability proporcionará uma discussão bem informada, quebrando com as práticas autoritárias do velho modelo de Estado, instigando posturas mais comprometidas por parte dos gestores públicos. Nesse aspecto, vale a pena ressaltar o entendimento de Robert Dahl em que "cidadãos silenciosos podem ser perfeitos para um governante autoritário, mas seriam desastrosos para uma democracia ${ }^{28, "}$.

Deste modo vislumbra-se a informação como parte essencial para a construção de uma democracia plena, pautada no livre acesso a questões de ordem pública, de modo a propiciar uma política cada vez mais transparente, participativa e responsável, inclusive no processo de emancipação humana, condição necessária para o desenvolvimento das liberdades conforme será abordada com maior enfoque no tópico seguinte.

\section{O DIREITO À INFORMAÇÃO COMO SUPORTE PARA O DESENVOLVIMENTO DAS LIBERDADES CIVIS}

Um dos grandes enfoques no que diz respeito ao desenvolvimento das liberdades do homem é o livre acesso às informações, principalmente aquelas que abrangem os setores públicos da administração Estatal, viabilizando com que assim os cidadãos possam ter o direito de exercer o controle político-social nos atos da gestão pública, fator esse que além de dar suporte para a prevenção da corrupção, vem a corrobar com o desenvolvimento das liberdades civis, consolidando assim com o próprio fortalecimento da cidadania e consequentemente da própria égide do Estado Democrático.

Nesse prisma, em que pese, o direito à informação e o desenvolvimento da liberdade, merece destaque o posicionamento de Amartya Sen, o qual evidencia de maneira clara o papel do processo de argumentação e de informação pública para a concepção de justiça e de democracia.

Para Sen, o "debate" e a "argumentação pública" têm sido abordados com mais frequência na filosofia política contemporânea. ${ }^{29}$ A justificativa permeia na relação intrínseca com a ideia de justiça e a prática da democracia deliberativa. Isso implica no modo de se constituir as eleições. Numa visão mais antiga da democracia, as eleições estavam condicionadas apenas ao exercício do direito ao voto secreto. Enquanto, partindo de uma perspectiva contemporânea, a votação secreta é sinônimo de um governo aberto e livre para o debate, que nos últimos anos tem se consolidado cada vez mais presente. Deste modo "A opinião pública e o

\footnotetext{
${ }^{26}$ JARDIM, José Maria. Transparência e opacidade do estado no Brasil: usos e desusos da informação governamental. Niterói: Ed. da UFF, 1999.

${ }^{27}$ VALLE, Vanice Regina Lírio do. Direito fundamental à boa administração e governança. Belo Horizonte: Fórum, 2011.

${ }^{28}$ DAHL, Robert. Sobre a democracia. Tradução de Beatriz Sidou. Brasília: Editoria Universidade de Brasília, 2009, p. 110.

${ }^{29}$ SEN, 2011, p. 358.
} 
debate, assim, ganham espaço nos governos democráticos, e a informação, nesse contexto, é a protagonista para a realização qualitativa daqueles" ${ }^{\text {30 }}$.

A posição de Sen, denota a importância das oportunidades de articulação e participação como dispositivos para o desenvolvimento e para a liberdade civil na formação de valores. ${ }^{31} \mathrm{~A}$ formação de valores deve ser dependente e ter estreita relação com a prática democrática, pois ela abarcar não apenas a regra da maioria, mas também nas novas normas e prioridades que venham a contemplar o direito das minorias ${ }^{32}$. Com a efetivação de diálogos abertos e de liberdade como pré-condição humana, é possível formar novos de espaços democráticos, e novas respostas para as necessidades jurídicas, políticas e sociais, pois mesmo que exercida de forma deficiente, o debate vem a ser o cerne na busca da argumentação pública como se pode se verificar:

Um esclarecimento aqui é necessário sobre os meios que podem ser utilizados na busca da argumentação pública. Debater e dialogar envolvem apresentar o próprio ponto de vista e prestar seria atenção nos argumentos do outro. Isso pode ser feito através da mídia ou de reuniões públicas, além de debates sobre temas relevantes, mas quando é difícil obter uma boa audiência, formas mais assertivas de comunicação podem também ser necessárias. Agitações, protestos e campanhas podem ser partes importantes da argumentação pública, conectando as pessoas umas às outras através da fala - mesmo que seja uma fala ruidosa ${ }^{33}$.

Nesse sentido, desponta a dimensão da argumentação pública e da comunicação no processo de identificação dos problemas, sejam de cunho político, social ou econômico, no âmbito das necessidades e do próprio funcionamento do sistema democrático, o que vem a representar um fator determinante para o desenvolvimento humano na busca por uma sociedade cada vez mais justa e paritária ${ }^{34}$. O fluxo de informações "pode desempenhar um papel importante tanto para expandir a compreensão da população, como para ampliar a prática política esclarecida", em que "Não só a força da discussão pública é um dos correlatos da democracia, com um grande alcance, como também seu cultivo pode fazer com que a democracia funcione melhor" 36 .

Ressalta-se nessa linha o posicionamento de Zambam quanto à importância das condições de liberdade na composição da estrutura social-política, e no apoio por uma imprensa livre e independente para promoção da liberdade de expressão e informação:

O exercício da liberdade tem implicação no processo de participação política e expressão, seja da vontade individual, seja na manifestação dos anseios da

\footnotetext{
${ }^{30}$ RAMINELLI E OLIVEIRA. Francieli Puntel e Rafael dos Santos de. O direito ao acesso à informação na construção da democracia participativa: uma análise da página do conselho nacional de justiça no facebook. Disponível em: http://www.egov.ufsc.br/portal/conteudo/o-direito-ao-acesso-\%C3\%A0informa\%C3\%A7\%C3\%A3o-na-constru\%C3\%A7\%C3\%A3o-da-democracia-participativa-uma-an\%C3\%A1lise-da. Acesso em: 20 jun. 2016.

${ }^{31}$ SEN. Amartya. Desenvolvimento como liberdade. Tradução Laura Teixeira Motta. São Paulo: Companhia das Letras, 2000, p. 208.

${ }^{32}$ GONÇALVES, Ângela. Argumentação racional pública e democracia Revista Opinião Filosófica, Porto Alegre, v. $03 ; \mathrm{n}^{\circ} .01,2012$.

${ }^{33}$ SEN, 2015, p. 396.

${ }^{34}$ ZAMBAM, Neuro José. A democracia contemporânea: entre a cruz e a espada. In: TRINDADE, André Karam; ESPÍNDOLA, Angela Araujo da Silveira; BOFF, Salete Oro. Direito, democracia e sustentabilidade: anuário do programa de pós-graduação stricto sensu da Faculdade Meridional. Passo Fundo, (RS): IMED, 2014.

${ }^{35}$ DRÈZE E SEN. Jean e Amartya. Glória Incerta. A Índia e suas contradições. Trad. Ricardo Donielli Mendes e Laila Coutinho. São Paulo: Companhia das Letras, 2015, p. 395.

${ }^{36}$ SEN, 2000, p. 208.
}

Revista de Direito Brasileira | São Paulo, SP | v. 16 | n. 7 | p. 242 - 255 | Jan./Abr. 2017 
sociedade. A necessidade de garantias legais do direito à livre expressão se inscreve nesse contexto, assim como, a liberdade de informação ou imprensa ${ }^{37}$.

Ainda, é necessário frisar o valor da transparência no processo de informação contra a prevalência da corrupção. Nesse aspecto, Sen destaca a Lei do Direito a Informação de 2005 implantada na Índia, seu país de origem, com a qual permite uma abertura ao público do acesso à informação pelos governantes, fomentando assim a própria accountability, no intuito de reduzir com os níveis de corrupção na esfera política ${ }^{38}$. Com a concretização desta lei, houve comportamentos mais proativos por parte dos cidadãos e seus governantes, bem como a instituição de sanções em caso de descumprimento. Isso tudo contribuiu ainda mais com o auxílio das novas tecnologias de informação, já que de uma maneira mais rápida, a disseminação por parte das informações entre a coletividade, preconizando assim uma nova tendência rumo a transparência.

Para Sen não existe uma "solução mágica" que de maneira isolada possa dar efetividade a accountability. Isso significa que se deve projetar alternativas a serem incorporadas juntamente com a accountability. Uma reforma dos sistemas de administração e de investigação, fundada em reformas legais que venham a reduzir a tolerância e a desonestidade financeiras, já se encontra amparada pela Lei de Direito à Informação e demais legislações esparsas. Tal alternativa pode ser calcada em um jornalismo investigativo que acompanhe a posturas daqueles que se comportem de maneira dúbia e sem prestar as devidas contas.

$\mathrm{O}$ advento desta lei implementada em grande parte dos países democráticos, inclusive no Brasil, veio a contribuir substancialmente para uma mudança de paradigma, principalmente no combate e fiscalização das ações dos agentes públicos e consequentemente da própria corrupção. Por mais que o progresso para enfrentar um ciclo vicioso de corrupção seja lento, "uma mudança comportamental podem ganhar impulso para alcançar uma velocidade inesperada", e "o que parece ser irremediavelmente impossível de mudar pode não ser tão remediável assim" é o que constata o economista. ${ }^{39}$

Deste modo, não se pode perder a esperança diante das dificuldades em efetivar a participação popular no acesso à vida pública e em movimentos a favor da accountability, fruto de demandas sociais que proclamam por uma mudança na forma de fazer política. Para o professor, isto significa que:

Existem evidências ainda não totalmente comprovadas de que algumas dessas mudanças estão começando a fazer a diferença. Se nos deixássemos levar pelos relatos da mídia, teríamos a impressão de que a corrupção está aumentando a galope. E certos tipos de corrupção, sobretudo a corporativa, de fato adquiriram proteções sem precedentes. Mas também é fato que, em certa medida, a corrupção tornou-se mais visível por causa do crescente escrutínio público, bem como dos novos mecanismos para expor a corrupção (especialmente em virtude da lei de acesso à informação). ${ }^{40}$

Em síntese, verifica-se que o direito à informação, e isto inclui a Lei de Acesso a Informação e o processo de accountability, juntamente com outros mecanismos de participação eletrônica e pública vieram para somar e renovar a formas de organização do Estado Democrático. Vem a ser consolidada uma nova forma de exercer política, reivindicar por direitos e interferir significativamente na gestão pública, e o reflexo disso é uma população mais

\footnotetext{
${ }^{37}$ ZAMBAM, Neuro José. A democracia contemporânea: entre a cruz e a espada. In: TRINDADE, André Karam; ESPÍNDOLA, Angela Araujo da Silveira; BOFF, Salete Oro. Direito, democracia e sustentabilidade: anuário do programa de pós-graduação stricto sensu da Faculdade Meridional. Passo Fundo, (RS): IMED, 2014.

${ }^{38}$ SEN, 2015, p. 158.

${ }^{39}$ SEN, 2015, p. $171-172$.

${ }^{40}$ SEN, 2015, p. 167.
}

Revista de Direito Brasileira | São Paulo, SP | v. 16 | n. 7 | p. 242 - 255 | Jan./Abr. 2017 
consciente e informada, assim como Zambam já enfatizava que “[...] as múltiplas formas de participação que ocorrem nas sociedades democráticas são decisivas para afirmar a importância da democracia na ação individual e coletiva das pessoas ${ }^{41}$ ".

O que importa, portanto, é correlacionar a ideia democracia com a participação, e isso envolve sugestões, opiniões e diálogos para se chegar a uma sociedade próxima do ideal, ou seja a uma administração comprometida, justa e transparente. Em que a transparência e o livre acesso às informações, não podem ser vistos como sinônimos de políticas públicas, mas sim, como princípios norteadores da democracia.

\section{CONCLUSÃO}

Nesse viés contata-se que o direito à informação, atrelado ao uso das tecnologias de informação e de comunicação, apresenta-se como um importante aliado e facilitador no acesso às informações, principalmente aquelas envolvendo a ordem pública e o interesse da coletividade. Isso se comprova diante da complexidade em dar um suporte efetivo no âmbito das pretensões democráticas, que para tanto, encontra resguardo na própria Constituição Federal artigo $5^{\circ}$, inciso XXXII, e em tratados internacionais, a exemplo da Declaração Universal dos Direitos do Homem sendo, portanto, reconhecido como um direito humano e basilar na promoção de direitos fundamentais.

A propósito, a própria Lei 12.527/11 se mostra um avanço na efetivação do direito à informação, pois sua criação concretizou o direito de acesso à informação, o que veio a fortalecer o controle social, possibilitando assim um maior controle e acompanhamento das ações dos governantes, o que reduziu os riscos resultantes da assimetria de informações. Tal acompanhamento, antes só se fazia possível após o enfrentamento de uma série de questões de ordem burocrática.

Ademais, juntamente com a Lei de Acesso à Informação, o ingresso à transparência e à accountability tornaram-se indispensáveis para efetivação de uma democracia com mais participação na formulação de políticas públicas, como é o caso do combate a corrupção, que atualmente se vê tão presente, isso tudo em virtude das demandas públicas que proclamam por mudanças nas formas de fazer política.

A abordagem de Amartya Sen sinaliza que o desenvolvimento humano só será possível após o enfrentamento dos tradicionais modelos políticos autoritários e a implementação de mecanismos de participação, através do diálogo, da argumentação pública, do exercício de reivindicação, além manifestações e organizações de caráter coletivo que venham a transformar e dinamizar as formas de fazer política no cenário atual. Será por meio dessas articulações que novos canais de diálogos abertos entre Estado e sociedade poderão ser consolidados, uma vez que, cidadãos conscientes e bem informados são peças-chaves para o funcionamento de uma boa política.

É preciso dizer, portanto, que a adesão efetiva da população nos assuntos de interesse público tem reflexos significativos sobre eventual decisão política do Estado e suas consequências na esfera social, por isso que o direito à informação deve ser concebido como pressuposto para o desenvolvimento das liberdades humanas e da própria cidadania. Para tanto, é necessária certa cautela ao acreditar que somente com o acesso à informação pública e à transparência será possível combater todas as mazelas do Estado Democrático, mas a contraponto, deve-se considerar que há um combate sério se concretizando, e que o progresso da verdadeira democracia não deve estar separado desse processo.

${ }^{41}$ ZAMBAM, 2014.

Revista de Direito Brasileira | São Paulo, SP | v. 16 | n. 7 | p. 242 - 255 | Jan./Abr. 2017 


\section{REFERÊNCIAS}

AYUDA, Fernando Galindo. Democracia, Internet y Gobernanza: una concreción. Revista Seqüência, Florianópolis, v. 33, n. 65, p. 33-56, 2012, p. 37.

BRASIL. Constituição da República Federativa do Brasil de 1988. Disponível em: http://www.planalto.gov.br/ccivil 03/Constituicao/Constituicao.htm. Acesso em: 17 mai. 2016.

BRASIL. Controladoria Geral da União. Acesso à informação pública: uma introdução à Lei 12.527, de 18 de novembro de 2011. Brasília, 2011a. Disponível em: $<$ http://www.cgu.gov.br/acessoainformacao/materiais-

interesse/CartilhaAcessoaInformacao.pdf $>$. Acesso em: 19 mai. 2016.

BRASIL. Transparência pública. Disponível em: <http://www.portaltransparencia.gov.br/controleSocial/documentos/FolderTransparencia.pdf >. Acesso em: 19 mai. 2016.

CARVALHO, Luiz Gustavo Grandinetti Castanho de. Liberdade de informação e o direito difuso à informação verdadeira. Rio de Janeiro: Renovar, 2003.

CASTELLS, Manuel. A sociedade em rede. São Paulo: Paz e Terra, 1999.

CEPIK, Marco. Direito à Informação: Situação Legal e Desafios. Revista IP - Informática Pública, Belo Horizonte, v. 02, n. 02, p. 43-56, dez. 2000.

CREMADES, Javier. Micropoder - a força do cidadão na era digital. São Paulo: SENAC.

DAHL, Robert. Sobre a democracia. Tradução de Beatriz Sidou. Brasília: Editoria Universidade de Brasília, 2009, p. 110.

DRÈZE E SEN. Jean e Amartya. Glória Incerta. A Índia e suas contradições. Trad. Ricardo Donielli Mendes e Laila Coutinho. São Paulo: Companhia das Letras, 2015.

GONÇALVES, Ângela. Argumentação racional pública e democracia. Revista Opinião Filosófica, Porto Alegre, v. 03; nº. 01, 2012.

HOHLFELDT, Antônio. As origens antigas: a comunicação e as civilizações. In: _; et al. Teorias da Comunicação: conceitos, escolas e tendências. Petrópolis: Vozes, 2007, p. 80.

JARDIM, José Maria. Transparência e opacidade do estado no Brasil: usos e desusos da informação governamental. Niterói: Ed. da UFF, 1999.

MANZANO FILHO, Gabriel. OEA defende o direito à informação. 2012. Disponível em: $<$ http://www.mndh.org.br/index.phpoption=com_content\&task=view\&id=113\&Itemid=45 $>$. Acesso em: 19 mai. 2016.

MENDEL, Toby. Liberdade de informação: um estudo de direito comparado. 2.ed. Brasília, DF: UNESCO, $2009 . \quad$ Disponível em: $<$ http://www.acessoainformacao.gov.br/acessoainformacaogov/publicacoes/liberdadeinformacao-estudo-direito-comparado-unesco.pdf>. Acesso em: 17 jun. 2016. 
MILL, John Stuart. Sobre a liberdade. Tradução Pedro Madeira. Ed. Especial. Rio de Janeiro: Nova Fronteira, 2011.

MÜLLER, Friederich. Democracia e República. In Rev. Jur., Brasília, v. 7, n. 77, p. 0107, fev./mar. $2006 . \quad$ Acessível em: http://www.planalto.gov.br/ccivil_03/revista/Rev_77/artigos/PDF/FriederichM\%FCller_Rev 77.pdf. Capturado em 05 de outubro de 2008

NETO, Guilherme Fernandes. Direito da Comunicação Social. São Paulo: Editora Revista dos Tribunais, 2004.

NINO, Carlos Santiago. $\quad$ La Constitucion de la Democracia $\quad$ Deliberativa.1. ed., 1 reimp. Barcelona: Gedisa Editorial, 2003.

RAMINELLI E OLIVEIRA. Francieli Puntel e Rafael dos Santos de. O direito ao acesso à informação na construção da democracia participativa: uma análise da página do conselho nacional de justiça no facebook. Disponível em: http://www.egov.ufsc.br/portal/conteudo/odireito-ao-acesso- $\% \mathrm{C} 3 \% \mathrm{~A} 0$-informa $\% \mathrm{C} 3 \% \mathrm{~A} 7 \% \mathrm{C} 3 \% \mathrm{~A} 30$-na-constru $\% \mathrm{C} 3 \% \mathrm{~A} 7 \% \mathrm{C} 3 \% \mathrm{~A} 30$-dademocracia-participativa-uma-an\%C3\%A1lise-da. Acesso em: 20 jun. 2016.

RAWLS, John, Uma Teoria da Justiça: Trad. Almiro Pisetta e Lenita M. R. Esteves - São Paulo: Martins Fontes, 1997.

SADALLA BUCCI, Eduardo. O acesso à informação pública como direito fundamental à cidadania. In: Âmbito Jurídico, Rio Grande, XII, n. 67, ago 2009. Disponível em: <

http://www.ambitojuridico.com.br/site/index.php?n_link=revista_artigos_leitura\&artigo_id=6490 >. Acesso em 16 jun. 2016.

SANTOS, Boaventura de Sousa e AVRITZER, Leonardo. Para ampliar o cânone democrático. In: SANTOS, Boaventura de Sousa (org.). Democratizar a democracia: os caminhos da democracia participativa. Rio de Janeiro: Civilização Brasileira, 3a ed. 2005.

SEN, Amartya. A ideia de justiça. Trad. de Denise Bottmann e Ricardo Doninelli Mendes.

São Paulo: Companhia das Letras, 2011.

SEN. Amartya. Desenvolvimento como liberdade. Tradução Laura Teixeira Motta. São Paulo: Companhia das Letras, 2000.

SILVA, José Afonso da. Curso de Direito Constitucional Positivo. 2a edição. São Paulo: Malheiros, 1996.

VALLE, Vanice Regina Lírio do. Direito fundamental à boa administração e governança. Belo Horizonte: Fórum, 2011.

VIEGAS, Weverson da Siva. O direito à informação como pressuposto para a participação popular no Estatuto da Cidade. Revista da Faculdade de Direito de Campos, Campos dos Goytacazes, RJ, v. 4/5, n. 4/5, p. 671-683, 2003/2004. Disponível em: $<$ http://bdjur.stj.jus.br/dspace/handle/2011/25696>. Acesso em: 26 set. 2016. 
ZAMBAM, Neuro José. A democracia contemporânea: entre a cruz e a espada. In: TRINDADE, André Karam; ESPÍNDOLA, Angela Araujo da Silveira; BOFF, Salete Oro. Direito, democracia e sustentabilidade: anuário do programa de pós-graduação stricto sensu da Faculdade Meridional. Passo Fundo, (RS): IMED, 2014. 